Journal of Social Sciences 8 (1): 29-32, 2012

ISSN 1549-3652

(C) 2012 Science Publications

\title{
Municipalities as Sports Multipliers
}

\author{
Rudolf Leber \\ Department for Sport Science, University of Vienna, \\ Auf der Schmelz 6, 1150 Wien, Austria
}

\begin{abstract}
Problem statement: It is generally agreed that sports must be made available for children and young people. The children and youth of urban areas should be encouraged to form meaningful sporting activities under the guidance of sport teachers. Approach: Based on a study of the leisure activities of the Vienna children and young people through the city of Vienna, the 'Sport and Fun' Halls was launched as a pilot project. Results: Following the successful implementation of the pilot project 'Sport and Fun-Halls', more locations and activities for the Vienna Youth have been anchored in sports policy. Conclusion/Recommendations: Given the safe and optimal training, leisure and exercise opportunities for children for children and young people, the expansion of other sports and recreational facilities in urban areas is recommended.
\end{abstract}

Key words: Sports multipliers, sports community, socialization, sport policy, children and adolescents

\section{INTRODUCTION}

One of the key concerns of the City of Vienna lies in providing optimum frame conditions for sport in all its manifold facets. In this age of networking and media coverage, any modern municipal administration will be interested in meeting international sports trends (City of Vienna, 2003).

Sports create interest for everyone and affect our entire society. $40 \%$ of Austrians are active in sports. The rest of them interested. Athletes have been great role models since ancient times and enjoy a high reputation. You can say sport permeates the whole society. Sport is Eros, he moves, he inspires and he is now more present than ever in newspapers, on television, on billboards, in movies, at live events. Sport mobilizes. Sport brings people together. A large part of the economy thrives on sports. Large corporations devalue their brands through it. After all, sport is for physical aesthetics, self-confidence, joy and often for community. It teaches health and fitness and is the epitome of success. The history of mankind is very clearly closely connected with sport. A pluralistic, democratic and open society engaged in sport will find the freedom to investigate possibilities and dependencies to oppose this.

Municipalities as sports multipliers: 'Sport and Fun' is the name of a pilot project launched in autumn 1996 as an initiative of the Vice-Mayor and City Councilor for Sports, Ms. Grete Laska. It was designed to offer Vienna's children and young people 'classic' outdoor sports and-above all-trendy sports in one central location, even during the cold season. Highly motivated amateur coaches help youngsters solve problems on-site and show the young participants how to play their favorite sports at a high standard and maintain this level. The fact that younger and older kids practice sports here in a practically conflict-free and totally relaxed atmosphere is a highly desirable and positive side effect. With no particular advertising efforts, practically through wordof-mouth alone, the pilot project at the 'Messehalle' proved a resounding success.

Yet the motto 'Sport and Fun' represents not only current sports services but also a maximum of openness to new impulses and trends in the world of sports; above all, it stands for joy, relaxation and happiness of the individual. Since October 1996, thousands of children and young people have made use of the 'Sport and Fun' services.

In an interview, Mr. Willi Göppert put it like this: "Modern-day leisure activities are strongly influenced by sports-not only for health reasons but rather because of the well-being and enjoyment derived from pursuing an enjoyable pastime. Of course, the wide variety of today's options plays an important role here".

While in the past games like tennis, golf and horse-riding were practiced by a specific elite stratum of the population, often as a status symbol, elite sports have all but disappeared today, as these disciplines, too, have undergone general socialization and social adjustment processes (Elias and Dunning, 2008; Ulas, 2008 and Ahmadi et al., 2010). According to Goppert, sports are practically the only field "where socialization and integration are as visible and tangible". Especially for "problem kids", sports offer a key possibility of developing a sense of 
responsibility and team spirit. All current tendencies of social work strive to involve the multiple aspects of sports. Many processes in sports practice are in fact based on interpersonal tolerance, on respect for other individuals and on "doing something together", so to speak, thus creating real-life integration.

While exclusion (of foreigners, black people, and political dissenters) is a fact of everyday life, sports-even individual sports embody unity and solitary. However, the idolization of 'sports gods' is a phenomenon that Göppert considers potentially dangerous.

In his opinion, this "idolization is economically controlled" - if Hermann Maier does not take part in the Kitzbühel downhill, this means a loss of money; at the same time, a few stakeholders (ski manufacturers, the media and the champion himself or herself) earn enormous sums while the overwhelming mass of spectators who buy the sports equipment (Hermann Maier's brand of skis is currently out of stock) get no chance to improve their personal skills.

Although Goppert accepts the fact that people try to emulate the exploits of professional athletes and even considers this useful phenomenon, he regards 'idols' as an extremely dubious development because they can be so easily (economically and/ or politically) instrumentalised.

As the director of the pilot project 'Sport and Fun' (for trendy sports), he deplores the fact that sports clubs-actually the backbone of sports in general-hardly pay any interest to these disciplines, thus forcing the City of Vienna to act as a driving force and animator. "Nobody joins in, that's the problem. There is very little interest on the part of clubs and associations. It's really a pity that the City of Vienna is once more obliged to step in to get things moving".

In Göppert's opinion, it is important "in this era of media and mass communication to keep a close watch on upcoming sports trends and developments in order to react to them with an eye to socialization and integration". Since clubs and associations remain diffident and have assumed a kind of wait-and-see attitude, it is crucial for the City of Vienna to keep an open mind to face these challenges.

In an era much interested in privatization and spinoffs, a perspective that assigns primacy to municipal innovations seems quite an extraordinary stance to take.

A central factor of the City of Vienna sports scene is provided by the sports halls, large-scale spotless venues and youth sports facilities managed by Municipal Department on its own account. Six round halls, three conventional sports halls and one largescale sports hall are available to athletes and sports lovers from 8 a.m. to 10.30 p.m. From I a.m. to 6 p.-., the halls are used by municipal schools on Mondays through Fridays and Saturdays mornings, while the hours from 6 p.m. to 10.30 p.m. are devoted to club training programmes for various types of sports (e.g., gymnastics, judo, wrestling, karate, handball, volleyball, basketball, fastball, soccer, field hockey) at favorable sports promotion tariffs (stipulated by the City Council). During weekends, club championships or large-scale sports events are organized at these venues.

Principally, it should be said that the sports services of Municipal Department are definitely not to be understood as competing with other providers of sports services and facilities (over 100 sports facilities on lots owned by the City of Vienna are rented to private associations or organizations); rather, it views its activities and above all the very affordable tariffs as a useful complement and addition to the overall spots service range. The geographic position of Vienna also offers opportunities for winter sports. Thus seven municipally-owned courses for crosscountry skiing are continuously kept in viable condition and generally taken care of by the Sports Office (City of Vienna, 2003).

The sports activities of the City of Vienna are equally important. Extracurricular sports services are in place to establish direct contacts with the city's youngsters. These activities encourage young people to engage more intensively in sports and to provide an introduction to various types of sports. They are conducted by the Municipal Department in co-operation with Verein Wiener Jugendkreis and various specialized associations.

Primarily, these activities aim at communicating basic knowledge about individual types of sports to the young participants. Secondarily, physical exercise within a larger group promotes the young people's interest in competitive sports (matching one's strength and skill against those of others). The efforts of Municipal Department are to forge a kind of link between persons who practice sports on a one-off basis and confirmed sports lovers who take regular exercise.

The individual disciplines selected for this purpose were chosen with the objective of providing a good overview of the various elementary forms of human movement. This inspired the choice of running, jumping and throwing. These pillars of sports activities were then supplemented by the inclusion of ball games. Later, it proved necessary to integrate winter sports, too, into the service programme, which was finally completed by adding water sports.

Experience has shown that many adults are difficult to motivate to engage in sports. For this reason, 
children and young people should be encouraged to counteract this trend. As a result, enthusiastic children will in turn persuade the parents to join in.

Municipalities and in particular the City of Vienna act as multipliers of sports in a wide variety of fields.

As early as the interwar period, the City of Vienna was aware of its duty to create sociallyoriented institutions and facilities for the masses to improve the quality of life of the population. This tradition was continued from the end of Second World War into the present.

Moreover, the City of Vienna has always met the task of providing the best possible conditions for physical exercise and sports. The socializing element of sports was deliberately supported and strengthened by the municipal administration in such diverse areas as sports facility construction, the school construction programme or the promotion of sports clubs and associations (City of Vienna, 2003).

Until a few years ago, this support was relatively undisputed and uncontested.

However, in the past few years, the public sector has been increasingly drawn into discussion about the economic feasibility of its commitment; the question of whether to privatize municipal activities, too, has assumed centre stage. With respect to spots, it must be said at this point that only a very few disciplines-such as golf or tennis-will be able to yield a profit if operated on a private-economy basis, i.e. with a view to generating revenue, while the remaining club sports activities and their infrastructure with just a few exceptions, would have to be discontinued if public support were suspended (Koehl and Bach, 2006).

The tariffs charged by the City of Vienna for sports services are generally conceived as social tariffs and can thus only minimize-but never cover-the facial loss.

The future discussion of this issue will show whether the broad, affordably-priced range of services can be continued or whether individual sectors will have to be left exclusively to market-economy principles; as a result, however, the practice of many types of sports on a mass-sport level would become a matter of the individual's private purchasing power.

To ensure the socialization of large groups of the population through sports, any discussion of the (improved) economic efficiency and use of sports must definitely be conducted on the basis of a very strict assessment and a review of all pros and cons involved.

\section{CONCLUSION}

Exercise and sport is understood primarily as an intentional and personal event, but the education system (kindergartens, schools, clubs) and educational influences are impacted by sports as well. In sports education, you start with a functional education idea, which understands the structural influences of the school system on educational intentions.

If you follow the basic research, it is clear that you have to deal intensively with the learning of movements in this light. The learning of movement can be the basis for education experience. Exploration and discovery learning is peculiar to children. Children are naturally curious and should be offered a variety, of movement possibilities.

What must be said here is very clear, plain and simple: movement is the basic perspective of our reality. Furthermore, the "movement, games and sports" concept can be developed from a wide variety of perspectives. The above-mentioned considerations are based on anthropological assumptions and understanding. Accordingly, movement is a basic need, involved in speaking and thinking in addition to a fundamental way of being human. Based on the ideas of the sport scientist Grupe (2008), movement for children and body experience is a design tool, because by moving them to experience the world they can shape and design it at the same. Because human motion is acquired, a need to move is involved in education.

The many opportunities in the leisure sector require not only sports, but also expanding and maintaining the best-suited venues. School sport should be given even greater attention. The "daily movement unit (gym class)-performed by trained physical education teachers" should be the goal. One should use all means possible to persuade the population to take part in active sports. Increased promotion of youth is a necessity. Recreational, educational and competitive sports can be used as appropriate integration services. Also, a redistribution of grant funds should be reconsidered in order to cope with the new (social) challenges.

The social significance of sport is now greater than ever and it needs a good framework to adjust the conversion processes to the social implications of development. Sports conquered the urban area and has outgrown its old territory (sports facilities). The city here has the necessary conditions to create a place for all to participate.

Environmental problems are another challenge for the sport and the community.

In the field of sports facility development, a balance between planning and finances can be found. Sport can thus be seen as one of the most important tasks of our time (integration, social dimensions, health, exercise), thus for the recreational, educational and competitive sports, the conditions necessary to create, 
to overcome limits and to build new bridges are present. From school sports to science-sports are an important specific of the community.

\section{REFERENCES}

Ahmadi, E., A.R. Tehrani, A. Ahmadi, E. Ahmadi and A.R. Tehrani et al., 2010. Prevalence of obesity, overweight and underweight among elementary school children in southern Iran, 2009. Am. J. Applied Sci., 7: 1439-1442. DOI: 10.3844/ajassp.2010.1439.1442.

Elias, N. and E. Dunning, 2008. Quest for excitement: Sport and Leisure in the Civilising Process, 2nd Edn., University College Dublin Press, Dublin, ISBN: 1904558437, p. 320.
Grupe, O. and M. Krueger, 2007. Einfuehrung in die Sportpaedagogik. 2nd Edn., Hofmann, Schorndorf, ISBN: 3778077619 , p. 352.

Koehl, W. W. and L. Bach, 2006. Leitfaden Für Die Sportstättenentwicklungsplanung. 1st Edn., Sport and Buch Strauß, Köln, ISBN: 393939078X, pp: 148.

Ulaş, A.H., 2008. Effects of creative, educational drama activities on developing oral skills in primary school children. Am. J. Applied Sci., 5: 876-880. DOI: $10.3844 /$ ajassp.2008.876.880 